\title{
PERANCANGAN SISTEM INFORMASI ADMINISTRASI KELURAHAN PADA KELURAHAN PASAR BARU KOTA TANGERANG
}

\author{
Hari Santoso', Heru Soetanto Putra², Aditya Pratama ${ }^{3}$
}

Program Studi Sistem Informasi ${ }^{1,3}$, Teknik Informatika ${ }^{2}$, STMIK Dharma Putra Tangerang, Indonesia E-mail: hari.santoso8687@gmail.com ${ }^{1}$, herusoetantoputra@gmail.com², adityapratama.office@ yahoo.com ${ }^{3}$

\begin{abstract}
The development of information from time to time continues to increase` this is supported by the development of more advanced and adequate technology so that information can be accessed quickly and precisely. Based on the 2014-2018 Pasar Baru Kelurahan Vision that has been established and efforts to support the achievement of the Tangerang City mission by optimizing the authority of information technology-based public services through improving the quality of population administration and civil registration services. In fact in the process of storing data from the results of each work unit is still storing files in the ordner so it takes a long time to find the file that will be needed. To overcome the problems that occur, the authors make the design of a new village market administration information system The system will be built using the PHP programming language and Microsoft Access database. This application can simplify and speed up section heads and employees in accessing their documents independently so that administrative services become more effective and efficient and provide convenience in the processing of urban operational data in data storage services.
\end{abstract}

Keywords : Technology, Data, Information, Administration

\begin{abstract}
ABSTRAK
Perkembangan informasi dari waktu ke waktu terus meningkat hal ini didukung oleh perkembangan teknologi yang lebih maju dan memadai sehingga informasi dapat diakses dengan cepat dan tepat. Berdasarkan Visi Kelurahan Pasar Baru Tahun 2014-2018 yang telah ditetapkan dan upaya untuk mendukung pencapaian misi Kota Tangerang dengan mengoptimalkan kewenangan pelayanan publik berbasis teknologi informasi melalui peningkatan kualitas pelayanan administrasi kependudukan dan pencatatan sipil. Pada kenyataanya dalam proses penyimpanan data dari hasil unit kerja masing-masing tersebut masih menyimpan file dalam ordner sehingga memerlukan waktu lama untuk mencari file yang akan dibutuhkan. Untuk mengatasi permasalahan yang terjadi maka penulis membuat perancangan sistem informasi administrasi kelurahan pasar baru Sistem akan dibangun dengan menggunakan bahasa pemrograman PHP dan database Microsoft Acces. Aplikasi ini dapat mempermudah dan mempercepat kepala seksi dan pegawai dalam mengakses dokumennya secara mandiri sehingga pelayanan administrasi menjadi lebih efektif dan efisien dan memberikan kemudahan dalam pengolahan data operasional kelurahan dalam layanan penyimpanan data.
\end{abstract}

Kata Kunci: Teknologi, Data, Informasi, Administrasi

\section{PENDAHULUAN}

Berdasarkan Peraturan Walikota No. 83 Tahun 2016 Tentang Kedudukan, Susunan Organisasi, Tugas dan Fungsi Serta Tata Kerja Kelurahan, Sekretariat mempunyai tugas menyelenggarakan kegiatan di bidang Administrasi Umum, Kepegawaian, Perencanaan dan Keuangan.

Uraian tugas Sekretaris Kelurahan
diantaranya adalah melakukan pembinaan administrasi perencanaan di lingkungan kelurahan, melakukan koordinasi dengan unit-unit kerja di lingkungan kelurahan dalam rangka penyiapan bahan-bahan untuk menyusun laporan kinerja instansi pemerintah lingkup kelurahan dan laporan kedinasan lainnya dan melakukan fasilitasi dalam pembangunan dan pengembangan e-government.
Berdasarkan visi Kelurahan Pasar Baru Tahun 2014-2018 dalam pencapaian misi Kota Tangerang adalah mengoptimalkan kewenangan pelayanan publik berbasis teknologi informasi melalui peningkatan kualitas pelayanan administrasi kependudukan dan pencatatan sipil.

Penelitian dari Lulu Luciana Putri, Muhammad Fauzi Zulkarnaen, dan Hasyim Asyari dengan judul Sistem Informasi Administrasi Kependudukan Kelurahan Rembige Berbasis Web. Dalam pembuatan Sistem informasi Administrasi Kependudukan Berbasis Web ini penulis menggunakan metode perancangan SDLC (Software Development Life Cycle) serta menggunakan MySQL untuk database. Penelitian yang dilakukan mulai dari proses perencanaan sampai dengan proses implementasi dan testing yaitu mampu menghasilkan sebuah aplikasi yang dapat digunakan 
untuk keperluan administrasi kelurahan Rembige berupa keperluan surat menyurat, laporan kependudukan, dan data penduduk (Luciana Putri et al., 2019)

Penelitian dari Guntur Ristian Febriantyo dan Purwatining tyas dengan judul Rancang bangun sistem informasi administrasi kelurahan Mugas sari semarang berbasis web. Kelurahan Mugassari Semarang adalah suatu pemerintahan yang menangani semua data-data kependudukan seperti permohonan pembuatan Kartu Tanda Penduduk, Permohonan pembuatan KK, surat keterangan kepindahan dan lain-lain. Diwilayah Kelurahan semua data ditangani dengan cara manual seperti terlalu banyak formulir yang dimana membutuhkan biaya yang besar, bila persyaratan yang dikumpulkan kurang lengkap. Permohonan pelayanan data kependudukan pada penelitian ini hanya berupa surat permohonan pembuatan KTP, surat permohonan pembuatan KK, surat kelahiran, surat kematian dan surat pindah atau dating. Metode pengembangan sistem yang digunakan dalam penelitian ini yaitu Waterfall, perancangan sistem menggunakan UML dan implementasi sistem menggunakan PHP dan MySQL. Hasil dalam penelitian ini adalah sistem informasi Kelurahan berbasis web diKelurahan Mugassari dapat menghasilkan laporan pelayanan KTP, kartu keluarga, kelahiran, kematian dan pindah datang yang efektif dan efisien bagi penduduk dan pegawai kelurahan Mugassari dan diharapkan dapat menyelesaikan permasalahan yang kependudukan pada kantor Kelurahan Mugas sari (Febriantyo \& Purwatiningtyas, 2018).

Penelitian dari Desi Eka Herlyviana, Dwi Januarita, dan Agus Priyanto dengan judul Perancangang Sistem Informasi Pelayanan Administrasi Kelurahan Karangklesem Dengan Metode Prototyping. Pelayanan administrasi Kelurahan Karangklesem yang masih manual dan kurangnya informasi mengenai persyaratanpersyaratan ketika akan mengurus surat pengantar atau keterangan menjadikan proses pelayanan membutuhkan waktu yang sangat lama sehingga pelayanan administrasi kurang efektif dan efesien. Proses perancangan sistem informasi ini akan menggunakan metode prototyping untuk membangun dan menerapkan sistem informasi pelayanan administrasi di kelurahan karangklesem. Sistem informasi administrasi kelurahan ini diharapkan mampu menjadi solusi dari permasalahan pelayanan administrasi saat ini khususnya di kelurahan karangklesem agar mempermudah masyarakat dalam mengurus surat pengantar dan keterangan. Sistem Informasi Pelayanan Administrasi Kelurahan merupakan sebuah aplikasi berbasis website penyedia pelayanan administrasi yang bisa diakses secara online yang menjangkau seluruh masyarakat agar lebih memudahkan masyarakat dalam proses pelayanan administrasi (Herlyviana et al., 2018).

Pada kenyataanya dalam proses penyimpanan data dari hasil unit kerja masing-masing tersebut masih menyimpan file dalam ordner, sehingga apabila diperlukan membutuhkan waktu lama untuk mencari file tersebut, disamping itu data yang diminta oleh instansi lain seringkali dibutuhkan waktu yang lama untuk mencari file yang dimaksud karena tidak teratur dalam penyimpanan data.

Berdasarkan permasalahan hasil analisis di Kelurahan Pasar Baru, untuk menunjang administrasi umum dalam penyimpanan data pada unit kerja masing-masing yang masih tidak tertata (dalam bentuk lembaran yang mudah hilang), pola pengarsipan seperti itu tidak ada backup data. Tujuan dari penelitian ini ialah membuat sebuah aplikasi sistem informasi administrasi kelurahan pasar baru Sistem akan dibangun dengan menggunakan bahasa pemrograman $P H P$ dan database Microsoft Acces.

\section{METODOLOGI PENELITIAN}

Adapun metodologi yang digunakan dalam penelitian ini terdiri dari ( Budiyantara et al., 2020):

1. Metode Studi Pustaka

Mengumpulkan data dan informasi melalui berbagai referensi yang berkaitan dengan penelitian ini.

2. Metode Pengumpulan Data

Mengumpulkan data melalui tanya jawab dan diskusi dengan Sekretaris Kelurahan dan proses pengumpulan data dan informasi dengan cara meninjau dan mengamati secara langsung objek penelitian.

3. Metode Analisis

Penulis memilih menggunakan Dynamic System Development Method (DSDM). Beberapa alasan penulis memilih metode $D S D M$ dibandingkan dengan metode lainnya antara lain:

a. Tahapan dalam DSDM lengkap, jelas, dan mudah dipahami sehingga proses pengembangan sistem menjadi lebih teratur dan mudah dilakukan.

b. Aplikasi yang penulis kembangkan termasuk ke dalam aplikasi sederhana dan tidak membutuhkan waktu yang lama dalam pengerjaannya.

c. DSDM dapat melibatkan pengguna dari awal sampai akhir pengembangan sistem sehingga sistem yang dikembangkan sesuai dengan kebutuhan pengguna.

d. DSDM bersifat fleksibel sehingga bila terdapat perubahan pada sistem dapat diatasi dengan baik.

4. Metode Perancangan

Dalam merancang sistem, digunakan diagram dengan notasi UML. Unified 
Modeling Language (UML) adalah bahasa yang telah menjadi standar untuk visualisasi, menetapkan, membangun dan mendokumentasikan artifak suatu sistem perangkat lunak (Hariyanto, 2004).

Perancangan system menggunakan Unified Modelling Language (UML) adalah sebuah bahasa yang telah menjadi standar dalam industri untuk visualisasi, merancang dan mendokumentasikan sistem piranti lunak. UML menawarkan sebuah standar untuk merancang model sebuah sistem. Dengan menggunakan UML kita dapat membuat model untuk semua jenis aplikasi piranti lunak, dimana aplikasi tersebut dapat berjalan pada piranti keras, sistem operasi dan jaringan apapun, serta ditulis dalam bahasa pemrograman apapun. Tetapi karena UML juga menggunakan class dan operation dalam konsep dasarnya, maka ia lebih cocok untuk penulisan piranti lunak dalam bahasa-bahasa berorientasi objek seperti C++, Java, C\# atau VB.NET. Walaupun demikian, UML tetap dapat digunakan untuk modeling aplikasi prosedural dalam VB atau C (Yuni Sugiarti, 2013).

Dengan menggunakan program PHP PHP 4.0 adalah versi PHP yang paling banyak dipakai pada awal abad ke-21. Versi ini banyak dipakai disebabkan kemampuannya untuk membangun aplikasi web kompleks tetapi tetap memiliki kecepatan dan stabilitas yang tinggi (Sani, 2018).

\section{HASIL DAN PEMBAHASAN}

\section{Perancangan Sistem yang diusulkan}

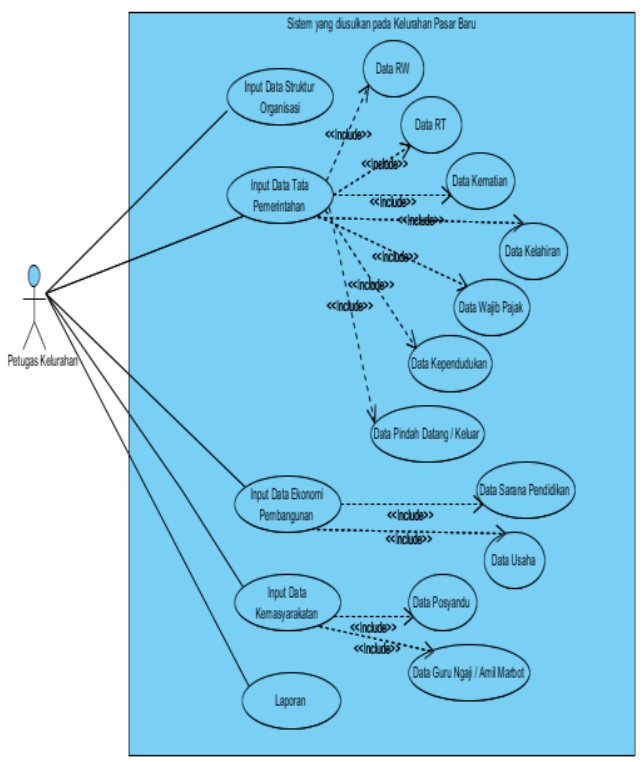

Sumber : (Santoso et al., 2019)

Gambar 1. Use Case Diagram Sistem yang Diusulkan
Aktor : Petugas Kelurahan

1. Petugas Kelurahan menginput data Struktur Organisasi

2. Petugas Kelurahan menginput data RW

3. Petugas Kelurahan menginput data RT

4. Petugas Kelurahan menginput data Kematian

5. Petugas Kelurahan menginput data Kelahiran

6. Petugas Kelurahan menginput data Wajib Pajak

7. Petugas Kelurahan menginput data Kependudukan

8. Petugas Kelurahan menginput data Pindah Datang / Keluar

9. Petugas Kelurahan menginput data Sarana Pendidikan

10. Petugas Kelurahan menginput data Usaha

11. Petugas Kelurahan menginput data

12. Posyandu

13. Petugas Kelurahan menginput data Guru Ngaji / Amil Marbot

14. Petugas Kelurahan membuat data Laporan

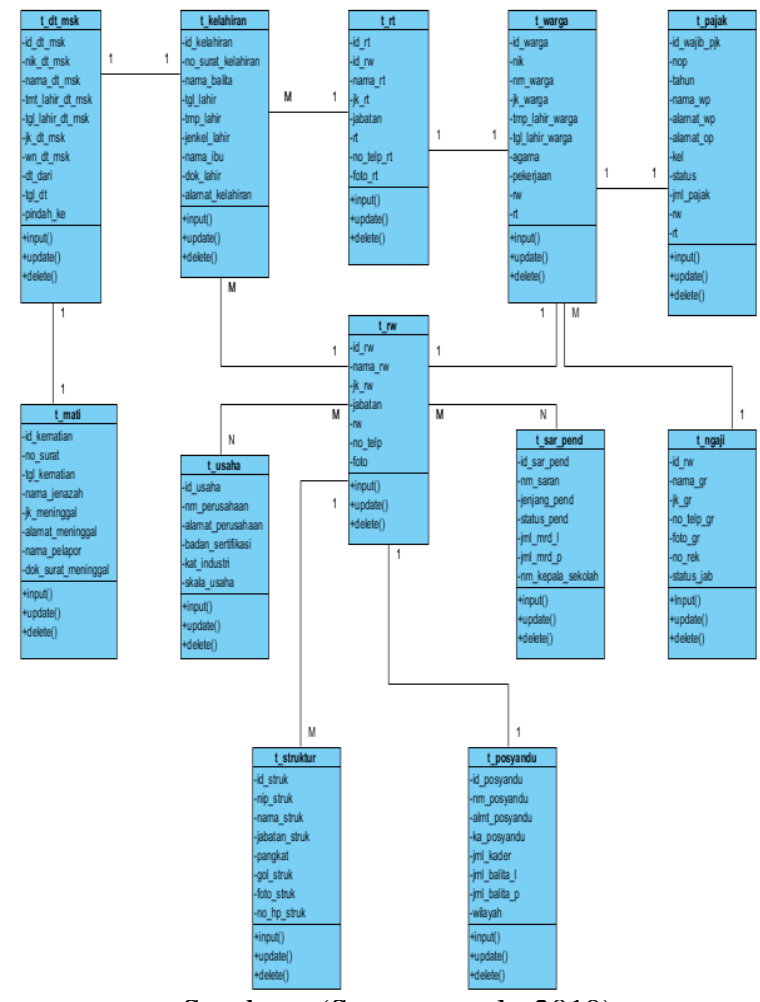

Sumber : (Santoso et al., 2019)

Gambar 2. Activity Diagram Input Data Kependudukan

1. Petugas Kelurahan masuk pada halaman menu utama setelah melakukan proses login.

2. Petugas Kelurahan memilih menu Tata Pemerintahan.

3. Petugas Kelurahan memilih sub menu Data Kependudukan. 
4. Petugas Kelurahan menginput Data Kependudukan, yang kemudian akan menyimpan data tersebut jika sudah selesai Petugas Kelurahan akan melihat halaman Data Kependudukan.

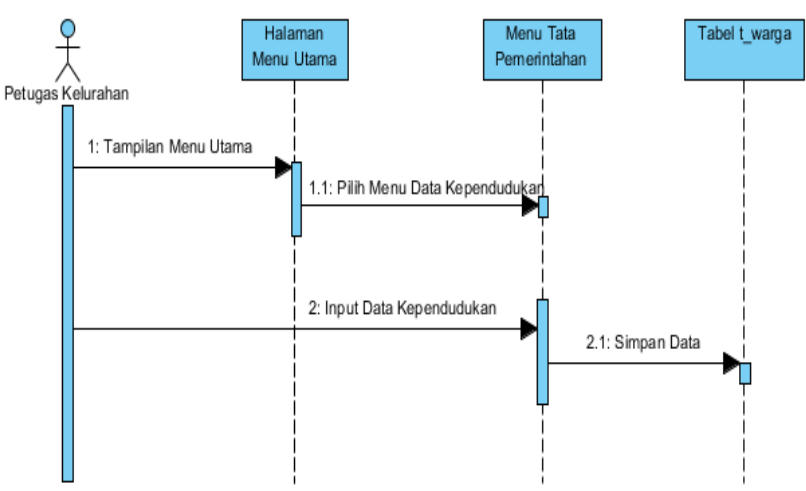

Sumber : (Santoso et al., 2019)

Gambar 3. Sequence Diagram Input Data Kependudukan

1. Tiga Life Line antar muka yang berinteraksi, diantaranya : Halaman Menu Utama, Menu Tata Pemerintahan, Database Kependudukan

2. Satu aktor yang melakukan kegiatan, yaitu :Petugas Kelurahan.

3. Empat messange spesifikasi dari komunikasi antar objek yang memuat informasi informasi tentang aktifitas yang terjadi, kegiatan yang dilakukan oleh aktor tersebut adalah masuk ke menu halaman utama pilih menu Tata Pemerintahan, Input Data Kependudukan dan simpan data.

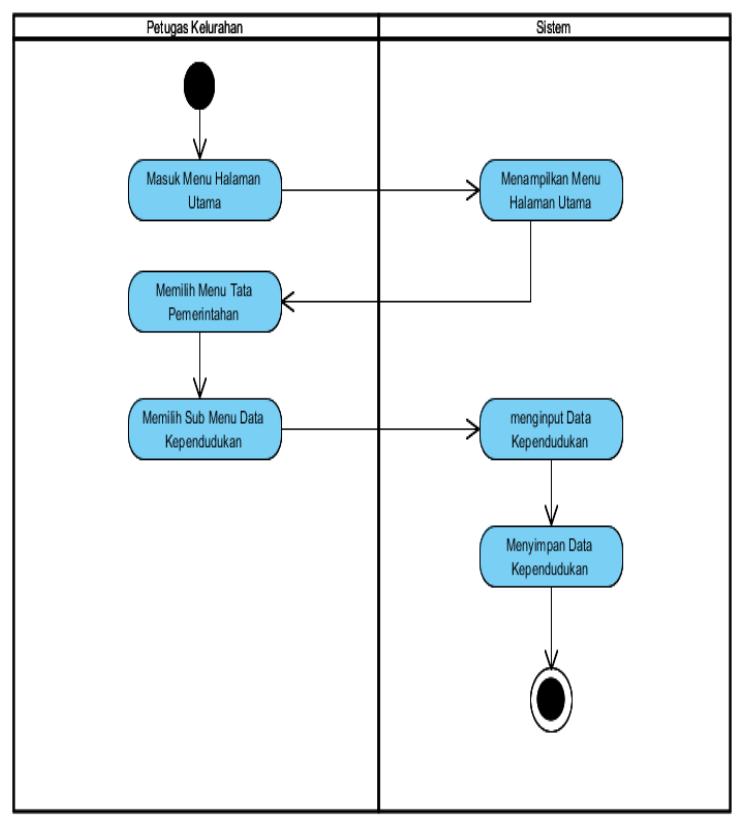

Sumber : (Santoso et al., 2019)

Gambar 4. Class Diagram yang diusulkan

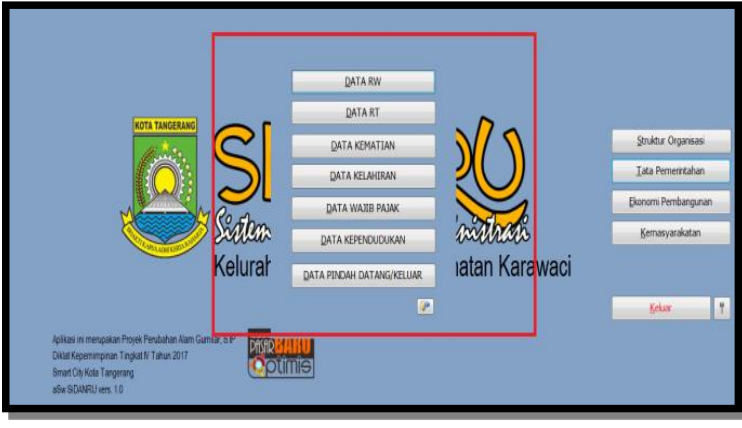

Sumber : (Santoso et al., 2019)

Gambar 5. Tampilan Menu Utama

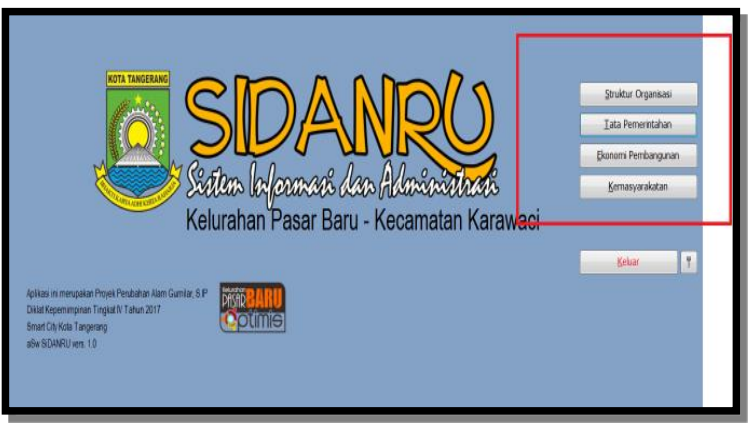

Sumber : (Santoso et al., 2019)

Gambar 6. Tampilan Menu Seksi Tata Pemerintahan

\section{KESIMPULAN}

Berdasarkan hasil penelitian dan pengamatan yang telah dilakukan di Kelurahan Pasar Baru, Kecamatan Karawaci, Kota Tangerang, maka dapat disimpulkan adalah sebagai berikut :

Pengembangan Sistem Informasi dan Administrasi Kelurahan dilakukan melalui pemodelan sistem berbasis objek yang mengedepankan masukan dari petugas kelurahan sebagai pengguna sistem. Aplikasi ini dapat mempermudah dan mempercepat kepala seksi dan pegawai dalam mengakses dokumennya secara mandiri sehingga pelayanan administrasi menjadi lebih efektif dan efisien. Dan aplikasi Sistem Informasi dan Administrasi Kelurahan pasar baru (Sidanru) memberikan kemudahan dalam pengolahan data operasional kelurahan dalam layanan penyimpanan data.

\section{DAFTAR PUSTAKA}

Agus Budiyantara, Irwansyah, Egi Prengki, P. A. P. (2020). Komparasi Algoritma Decision Tree, Naive Bayes Dan K-Nearest Neighbor Untuk Memprediksi Mahasiswa Lulus Tepat Waktu.

Febriantyo, G. R., \& Purwatiningtyas. (2018). Rancang Bangun Sistem Informasi Administrasi Kelurahan Mugassari Semarang Berbasis WEB. Prosiding SENDI_U 2018, 334-340. 
Hari Santoso, Heru Soetanto Putra, A. P. (2019). Perancangan Sistem Informasi Administrasi Kelurahan Pada Kelurahan Pasar Baru Kota Tangerang.

Hariyanto, B. (2004). Rekayasa Sistem Berorientasi Objek. Informatika.

Herlyviana, D. E., Januarita, D., \& Priyanto, A. (2018). Perancangan Sistem Informasi Pelayanan Administrasi Kelurahan Karangklesem Dengan Metode Prototyping. 169-174.

Lulu Luciana Putri, Muhammad Fauzi Zulkarnaen, H. asyari. (2019). Sistem Informasi Administrasi Kependudukan Kelurahan Rembige Berbasis Web. Jurnal Manajemen Informatika Dan Sistem Informasi, 2(1), 57. https://doi.org/10.36595/misi.v2i1.82

Sani, A. (2018). Penerapan Metode K-Means Clustering Pada Perusahaan. Jurnal Ilmiah Teknologi Informasi, 353, 1-7.

Yuni Sugiarti. (2013). Analisis dan Perancangan UML (Unified Modeling Language) Generated VB.6. Graha Ilmu. 
